\title{
Vector large-scale overview plan in a Swiss cantonal administration
}

\author{
Cristina M. Iosifescu Enescu ${ }^{\mathrm{a}}$ *, Andreas Gantner ${ }^{\mathrm{b}}$, Simone Würsch ${ }^{\mathrm{a}}$ \\ ${ }^{a}$ Canton of Zurich, Building Department, cristina.iosifescu@bd.zh.ch, simone.wuersch@bd.zh.ch \\ ${ }^{b}$ Eberhard Bau AG, andreas.gantner@eberhard.ch \\ * Corresponding author
}

Keywords: Overview plan, Vector plan, Overlay, Cadastral surveying data

\begin{abstract}
:
Switzerland has a long history of research regarding its overview plans. Such hand-drawn overview plans reached the status of cartographic works-of-art. The ETH Professors Herbert J. Matthias (cadastre) and Ernst Spiess (cartography) developed a detailed manual (Matthias and Spiess, 1995) on this subject. The Zurich cantonal administration invested a lot of effort in the creation of this plan for the Canton of Zurich.

With the availability of cadastral surveying data in digital format, the Swiss cadastral surveying introduced the basic cadastral surveying plan (Cadastre.ch), which is a uniform raster plan encompassing the whole of Switzerland. The creation of this plan is in the obligation of each canton and its content is automatically derived from the cadastral surveying data.
\end{abstract}

However, this raster plan did not satisfy the cartographic expectations of the Canton of Zurich. The main demand was that the overview plan is transparent, adequate to superimpose it on thematic maps, instead of using it as background. The advantage of having the overview plan in foreground is that the symbolisation of the thematic maps may be opaque and this does not hinder the spatial orientation.

The overview plan should also be available in vector, not only in raster form. Therefore, in contrast to the basic cadastral surveying plan, we decided that we need an overview plan with no colour-filled surfaces. Surfaces other than buildings would be broken into lines, and overlapping lines deleted. Not being allowed to fill the street surfaces with white, we have to delete delimiting lines that cross streets and cut the streets and other objects under bridges. For the forest, we generated a random-point texture with sufficient distance between points, so that a thematic map below this plan would still be readable.

Moreover, we classified the cadastral surveying geometries similarly to the hand-drawn visualisation, which would turn the digital overview plan in a valuable successor of the analogue one. Only a selected spectrum of objects available in the cadastral plan composes the overview plan. Similar to the basic cadastral surveying plan, we use the official cadastral surveying data. We decided not to apply geometrical generalisation, due to the large scale (1:500 to 1:10 000).

A first automation was built with ArcGIS Model Builder, and receives as input the cadastral data, giving as output the data prepared and classified for the symbolization of the overview plan. Currently, this model is run every three months and generates automatically the updated geometries for the overview plan. The geometries are then represented based on their attributes, using the same symbolisation as in the original hand-drawn plan. The degree of detail is adapted to a scale-dependent symbolisation - with scale thresholds being specified to control when street labels, buildings and cadastral lot numbers appear.

Furthermore, there are some special geometries in this overview plan, which were vectorised from the hand-drawn plan, for example the slope representation as small triangles (see figure1), or the contour-lines, which are smoother than the ones automatically generated from the digital terrain model. These geometries are additional to the cadastral surveying data, and represent an area of further work for the current automation of the overview plan. Moreover, further improvements are needed regarding some overlapping objects. 


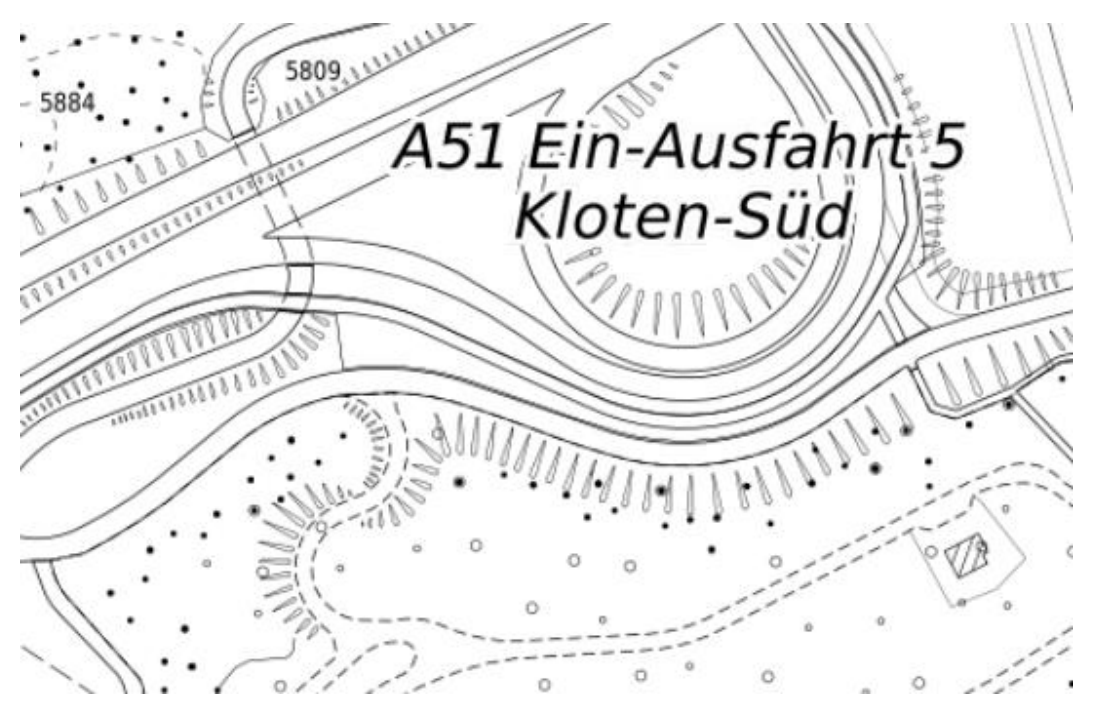

Figure 1. Slope representation, digitised from the hand-drawn overview plan

Used mainly for the orientation, superimposed on many different thematic maps, the overview plan of the Canton of Zurich is much appreciated by the customers of our Web GIS products and services. Our final aim is to produce an entirely automatized process, which we could run frequently to produce the overview plan with high cartographic quality.

\section{References}

Matthias, H. J., and Spiess, E. (1995). Amtliche Vermessungswerke Band 4: Topographische Grundkarte-der Uebersichtsplan. Verlag Sauerländer

Cadastre.ch. https://www.cadastre.ch/en/services/service/bp.html. Accessed on 18.06.2021. 